GLOBAL JOURNAL OF

Community Psychology Practice

PROMOTING COMMUNITY PRACTICE FOR SOCIAL BENEFIT

\title{
Photovoice as a Research-Intervention Tool for Youth Neighborhood Activism in Societally Vulnerable Contexts
}

\author{
Manuel García- \\ Giulia Guariso V Virginia Paloma Samuel Arias $\quad$ Rocío Garrido Ramírez \\ Università Cattolica \\ del Sacro Cuore, Italy \\ Universidad de Sevilla, Spain
}

Keywords: Activism, empowerment, neighborhood, participation, photovoice, psychological sense of community, youth

Author Biographies: Giulia Guariso is a community psychologist form the Catholic University of Milan and member of the Italian society of community psychology (SIPCO). She is currently specializing in systemic psychotherapy at the Mara

Selvini Palazzoli School and her interests include transcultural psychology, building of cultural adolescence identity, maternity and education strategy of immigrant women, and acculturation psychology process. Over the past years, Giulia has also acquired extensive experience both in research and field work whit fragile communities, with a special focus on the development of families ties in fragile contexts. Virginia Paloma, Ph.D., is Professor of Community Psychology at University of Sevilla, Spain. She is a staff member of CESPYD, the Center of Community Research and Action at University of Sevilla. Her research interests include the keywords of activism, liberation, resilience, empowerment, social change, well-being, and social justice in contexts of cultural diversity. She is currently leading a multidisciplinary partnership with the aim of constructing a multilevel, systemic, and dynamic model of migrant well-being which will permit to guide social interventions and public policies. In the context of the humanitarian crisis of refugees in Europe, she is interested in the development of capacitybuilding programs addressed to professionals to respond to the mental health's needs of this population. Samuel Arias Sánchez, PhD. is assistant professor in the Department of Social Psychology at the University Pablo de Olavide, in Seville. He has a Master in Human Resource Management, a Master of Advanced Studies in 
Brain and Behavior and a Master in Organizational and Work Psychology at the University of Seville. He is also part of the Human Activity Laboratory of the University of Seville and has published several articles and book chapters about different topics such as autobiographical memory, culture, education and work activity. Rocío Garrido is a Community Psychology doctoral student at the University of Seville, Spain. Her dissertation entails defining and promoting cultural competence from a social justice perspective at different levels (i.e. individual, organizational, community and socio-political). She is member of CESPYD, the Center of Community Research and Action at University of Seville, where she has been granted a scholarship to work as a researcher in the department of Social Psychology. Her interests are research-action related to complex migration flows, wellbeing and empowerment. Manue/ Garcia-Ramírez, Ph.D., is Professor of Community Psychology at University of Sevilla, Spain. He is the Coordinator of CESPYD, the Center of Community Research and Action at the University of Sevilla and the Founding Co-Director of the Master in International Migrations, Health and Wellbeing at this University. His research interests have been focused in the development of Community-Based Participatory Research (CBPR) initiatives aimed at ensuring equitable conditions toward migrants and ethnic minorities in Europe in the fields of health, public policy, integration, and reception processes.

Recommended Citation: Guariso, G. Paloma, V., Arias, S., Garrido, R., GarcíaRamírez, M. (2016). Photovoice as a Research-Intervention Tool for Youth Neighborhood Activism in Societally Vulnerable Contexts. Global Journal of Community Psychology Practice, 7(3), pages 1-18. Retrieved Day/Month/Year, from (http://www.gjcpp.org/).

Author Notes: This research project was funded in part by a grant from the Ministry of Science and Innovation of Spanish Government (PSI2011-25554). We would like to express our gratitude to both the young people who participated in this study and Sergio Cruz-Pozuelo for his valuable collaboration as art therapist during the intervention process.

Correspondence concerning this article should be addressed to Giulia Guariso, Department of Psychology, Università Cattolica del Sacro Cuore. Largo Gemelli, 1. 20123 - Milano, Italy. E-mail: giulia.guariso@fastwebnet.it 


\title{
Photovoice as a Research-Intervention Tool for Youth Neighborhood Activism in Societally Vulnerable Contexts
}

\begin{abstract}
Teenagers who live in vulnerable neighborhoods have a higher probability of entering into a vicious circle where they suffer the consequences of an unfair structure and, at the same time, contribute to the maintenance of it. A researchintervention with photovoice was carried out with youth from a vulnerable multicultural neighborhood on the outskirts of Seville (Spain). The objective was to increase the teenagers' neighborhood activism through an increase in their psychological sense of community, forecast of future participation, and empowerment. Young girls with different cultural roots, between the ages of 13 and 18 years old participated. After the photographs were taken by the participants, a space was opened for reflection on the strengths and challenges of the neighborhood. The photographs were worked on using artistic techniques to express the desired changes and then the group discussed how to make effective changes. Lastly, the extended community was involved through a photography exhibition. We measured the variables of interest through a prepost questionnaire given to the participant group and to a comparison group. Complementary, narratives which emerged during the meetings were analyzed. Participants increased their level of psychological sense of community and their wish to participate in the future, but continued with the same level of empowerment. Theoretical contributions and useful suggestions for researchintervention with photovoice are discussed.
\end{abstract}

Although people's daily lives today are more frequently spent in dispersed settings, neighborhoods maintain an important role as a point of reference for the construction of the inhabitants' personal and social identities and for satisfying their need for a sense of belonging (Tartaglia, 2006).

Furthermore, neighborhood conditions significantly impact the level of activism and well-being of their inhabitants. Vulnerable neighborhoods characterized by the insufficient provision of resources and services limit the wellbeing and endanger the identity construction process carried out by teenagers (Rankin \& Quane, 2002). Communities with high levels of crime, drug dealing, and other indicators of low quality of life are indeed typically characterized by minimal neighborhood activism among youth (Kelly, 2009). It appears therefore necessary to find appropriate research-intervention methods to prepare teenagers with the ability to increase their neighborhood activism in order to change those elements of their environment which impede their well-being.

Using the photovoice methodology, this research-intervention experience aimed to increase the level of youth neighborhood activism in a multicultural societally vulnerable neighborhood in the outskirts of Seville (Spain). This study defines neighborhood activism as the process in which teenagers work towards change in neighborhood conditions (Gilster, 2012). Photovoice is a researchintervention strategy whereby the participants take photographs that are later used as stimulus for group reflection on the strengths and challenges of their neighborhood for promoting both an individual and a social change (Nicotera, 2007). This study understands that the environment 
in which everyone lives exercises significant influence over individual behavior. At the same time, the individual can change the environment in which he/she is placed, in a relationship of reciprocal influence (Balcazar et al., 2012; Paloma \& Manzano-Arrondo, 2011). From this perspective, photovoice emerges as a strategy to facilitate the youth's awareness about the influence the neighborhood exerts on their life and to fuel youth neighborhood activism for the transformation of the environmental conditions.

In what follows, we contextualize this study by showing the situation of "Su Eminencia" neighborhood in southern Spain as a vulnerable context for young people. We then expose the theoretical basis upon which this study is constructed. Later, we present the methodology carried out and the results obtained. We conclude by discussing the main theoretical contributions that emerge from this pilot study and useful suggestions for future researchintervention with photovoice.

\section{An Overview of Su Eminencia as a Vulnerable Neighborhood}

The neighborhood "Su Eminencia" is located in the capital of Andalusia (Seville), the southernmost region of Spain. The neighborhood originated in the 1940s, a time when a strong influx of migration was reported from diverse provinces in Andalusia and from Portugal towards the Andalusian capital.

Following those changes, the urbanization of the city's periphery grew in a rapid and disorganized manner, creating a labyrinth of narrow streets built from recycled materials, without any hydraulic, sewer, or electricity systems (Torres, 2005). Not until the 1960s, and thanks to a strong mobilization of the inhabitants, did local administration provide connections to the city's sewer and electricity systems. In the last few years this neighborhood has received a high percentage of migrants coming mainly from Bolivia, Colombia, China, Morocco, and Romania (Torres, 2011). In fact, the neighborhood can be recognized by the diverse number of commercial activities that migrants manage in this area of the city.

Eighteen percent of households in the "Su Eminencia" neighborhood are in a situation of exclusion (Ayuntamiento de Sevilla, 2012). Among the most relevant problems in the neighborhood are the lack of economic resources, unemployment, an uneducated population, widespread drug dealing, drug addiction, and crime (Torres, 2011). These conditions are associated with a psychosocial profile in which teenagers often perceive themselves as victims of uncontrollable superior forces, lack confidence and the ability to gain competence to achieve success in life (Moane, 2003). Furthermore, this experience usually produces conformist behavior, passivity, and a life based on the present moment (Martín-Baró, 1987). Thus, the experiences lived in disadvantaged neighborhoods can become naturalized and interiorized by the younger generations, undermining their membership in community organizations (Wilson, 2000). Accordingly, Putman (2000) notes that "people with lower incomes and those who feel financially strapped are much less engaged in all forms of social and community life than those who are better off" (p. 193). As a consequence, the inactive behavior of teenagers contributes to the maintenance of the neighborhood's vulnerability, thus hindering their ability to leave this vicious cycle of oppression.

These circumstances require researchintervention processes that break this vicious circle through a transformative process where teenagers become active agents of change in their environments. Given the relationship between neighborhood inequity and well-being, neighborhood activism presents an important form of participation to 
address neighborhood problems (Gilster, 2012). We propose the photovoice strategy to fuel the involvement of youth in vulnerable neighborhoods.

\section{Photovoice to Promote Youth Neighborhood Activism}

Photovoice is a research-intervention strategy whereby, through the use of photographs taken by the participants, group reflection on the challenges and the strengths of their community is promoted with the goal of setting in motion individual and social change (Nicotera, 2007). Wang and Burris (1997) define photovoice's main objectives as: to allow people to understand the strengths and challenges of their community, to encourage group dialog and reflection about the challenges identified, and to favor processes of change in the community through the involvement of participants. Photovoice has been used in different contexts, involving participants from different genders, ages, nationalities, and cultural backgrounds (Baker \& Wang, 2006; Killion \& Wang, 2000; Oliffe \& Bottorff, 2007).

Photovoice allows the collection of important data on how places are experienced by people, thanks to the group reflections on the dynamics of life in these spaces. Furthermore, photovoice can increase the involvement and the collective interest in the community's issues by inviting people to become advocates for their own and the community's well-being (Wang \& Burris, 1997). Overall, photovoice helps to find out and activate the youth's awareness of their community and to give them the possibility of making their voice heard and to take action in their environment. For these reasons, community researchers have used the photovoice methodology as a research-intervention tool (e.g., Wang, Morrel-Samuels, Hutchison, Bell, \& Pestronk, 2004; Wilson et al., 2007; Strack, Magill, \& McDonagh, 2004). To our knowledge, only one other study implemented in southern Spain has used photovoice methodology among young people (Soriano \& Cala, 2014). Different from that study, our work uses photovoice methodology with art therapy technique, showing how different art practices can be combined in an innovative way to achieve the goal of promoting youth neighborhood activism.

Neighborhood activism is defined as the process by which teenagers work to bring change to the conditions of their neighborhood (Gilster, 2012). The importance of this process for youth goes beyond the immediate impact of their actions, as it provides them with opportunities to acquire significant civic and social skills critical to navigating and transforming their environment in adulthood as well (Kelly, 2009). Many studies have confirmed that neighborhood activism is related to the concepts of psychological sense of community, community participation, and empowerment (Garcia, Giuliani, \& Wiesenfeld, 1999; Prezza et al., 2001). These are strongly interrelated through ties of mutual influence and are essential elements for ensuring the well-being of individuals and communities.

A psychological sense of community refers to "a feeling that members have of belonging, a feeling that members matter to one another and to the group, and a shared faith that members' needs will be met through their commitment to be together" (McMillan \& Chavis, 1986, p. 9). Several studies have underlined the importance of a psychological sense of community related to the neighborhood in the transitional adolescent stage (Pretty, Conroy, Dugay, Fowler, \& Williams, 1996). Cicognani, Zani and Albanesi (2008) concluded that psychological sense of community showed a positive correlation with the youngsters' involvement in the community. Photovoice promotes the reflection and expression of the teenagers' points of view about their neighborhood, allowing 
the respective challenges to be heard, and increasing awareness of the strengths available in the community. Sharing experiences in the group facilitates the creation of a sense of emotional closeness and a stronger sense of belonging to the neighborhood.

Community participation is defined as people "actively belonging to formal and informal groups and making use of community organizations" (Cotterell, 1996). That is, community participation is a deliberate process, free and collective, which generates new relations aimed at achieving goals shared by the different actors involved. Community participation is considered the engine of change and transformation for individuals and communities (Montero, 2006). In such contexts, friendships and social networks stimulate the development of competencies and resources, which cannot be acquired from familial or domestic environments (Cotterell, 1996). Dumont and Provost (1999) observed that participation in the community prevents negative effects of stress and is correlated with reduced involvement in violent acts at school. Moreover, it can also moderate the effects of poor family relationships by providing a structure for increased supervision (Vieno, Nation, Perkins, \& Santinello, 2007). Community participation seems to be an important mechanism for empowerment development as participants can gain experience organizing people, identifying resources, and developing strategies for achieving goals (Aguiar, 2013; Zimmerman, 2000). Photovoice creates a space for collective reformulation of problems and possible solutions, being a vehicle to favor critical awareness and to increase community participation in order to enact positive change in the neighborhood.

Empowerment is defined as a multidimensional process which increases the power of individuals, by using the abilities they already have in their lives, in the groups to which they belong, in the community of which they are part, to react and act in the most appropriate way relative to what they define as important (Rappaport, 1987). Zimmerman and Rappaport (1988) stated that being involved in the decision-making process about neighborhood's issues or participating in grassroots organizations could develop a sense of efficacy in the context and foster growth in personal and community empowerment. Gilster (2012) suggests that working for the good of the neighborhood is associated with having a sense of control over one's life and the social context in which one lives. During the photovoice process, teenagers participate in activities addressed to the extended community where they have the opportunity to communicate their ideas to improve the neighborhood. Participants tend to have an active role, taking a first step in experiencing the power of action and modifying their environment. This type of experience usually has an effect on the level of empowerment in teenagers.

\section{Method}

\section{Participants}

Eight young women between the ages of 13 and 18 from a low socioeconomic status participated in the researchintervention's participant group. Five of them were Spanish, two Moroccan, and one Peruvian. Eight young people also participated in the researchintervention's comparison group. Participants in the comparison group had similar age and socioeconomic status as participants in the intervention group. All participants attended a grassroots youth organization called "El Escalón Salesiano" in the Su Eminencia neighborhood. On the basis of what emerged from the organization's staff during the planning phase, we decided to focus on the point of view of young womenas this group seems to have fewer opportunities to influence their 
neighborhood, despite their higher chance of living permanently in the community.

The organization primarily targets children and teenagers between the ages of 4 and 18 and offers them a vast portfolio of educational and leisure activities with a high participation rate, ensuring the existence of a wellestablished connection with the community. Our research team developed a strategy to access potential participants based on showing attractive announcements on the organization's walls and asking the organization's leaders about their collaboration in accessing interested young people in our project. Participants were rewarded with certificates of participation and with the possibility of winning a camera for making the most representative photograph of their neighborhood.

\section{Instruments}

A self-report questionnaire was administered to both the participant and comparison group twice: before and after the photovoice was implemented in the participant group. The questionnaire was composed of the following variables.

Personal profile. The following data were asked for in the beginning of the questionnaire: age, gender, cultural origin, and years of residence in the neighborhood.

Psychological sense of community. This variable was measured through the Sense of Community Index (SCI-2; Chavis, Lee, \& Acosta, 2008). The scale is composed of 24 items and is divided on four subscales: reinforcement of needs ("Being a member of this community makes me feel good"), membership ("I can trust people in this community"), influence ("I have influence over what this community is like"), and shared emotional connection ("I expect to be a part of this community for a long time"). The scale is a Likert-type response with five options (from 1, strongly disagree, to 5, strongly agree) and shows an internal consistency with a Cronbach's alpha value of .85 .

Forecast of future participation in the neighborhood. This variable was evaluated through a reformulation of the items of the sub-scale Community Participation from the Perceived Community Support Questionnaire (PCSQ; Herrero \& Gracia, 2007). The subscale is composed of five items and measures the level of involvement in the neighborhood's activities that people would like to do in a proximal future. Some items are "Among my plans in the short-medium term I hope to collaborate more in organizations and associations in my community" or "Among my plans in the short-medium term I wish to collaborate in some social or civic groups in my community." The scale is a Likerttype response with five options (from 1 , strongly disagree, to 5, strongly agree)and shows an internal consistency with a Cronbach's alpha value of .85.

Empowerment. This variable was measured through the Perceived Control Scale (Israel, Checkoway, Schulz, \& Zimmerman, 1994). The scale is composed of 12 items at the individual ("I have control over the decisions that affect my life"), organizational ("I can influence the decisions that this organization makes"), and community levels ("I can influence decisions that affect my community"). The scale is a Likert-type response with five options (from 1, strongly disagree, to 5, strongly agree) and shows an internal consistency with a Cronbach's alpha value of 85 .

\section{Procedure}

For the implementation of this project, a collaborative relationship was established between community psychologists from both the Coalition for the Study of Health, Power, and Diversity from the Universidad de Sevilla (García-Ramírez, Albar, \& Paloma, 2010) and the Università Cattolica del Sacro Cuore, and practitioners of the grassroots youth organization "El Escalón Salesiano." The 
plan of the project was negotiated with the members of this organization, according to action-research guidelines and community psychology values (Suarez-Balcazar, Harper \& Lewis, 2005).

Photovoice was carried out through a research-intervention process over five months. Three formal meetings and multiple informal encounters with the participants were held as well as a final exhibition open to the entire community. The meetings, which took place at the youth organization, were led by two facilitators and one observer in charge of taking notes on salient events.

The first meeting included administration of the pre-test, the research team members' and participants' introductions, and an explanation of the objectives and planned activities. A group walk was conducted throughout the neighborhood. While participants talked informally with research team members, each teenager used her own cellular phone equipped with a camera to take photos of the neighborhood. The choice to use an instrument owned by the participants was made based on the desire to make them aware of the resources in their possession. At the end of the meeting, the participants were invited to collect and send to the research team, via "What's app" or e-mail, photos capturing the neighborhood's strengths and challenges. Our purpose was to favor a deeper personal exploration of the aspects dealt with in group and to facilitate continuity in the second meeting.

The second meeting aimed to gather the stories which were spring-boarded from the photos previously made, with the intention of developing individual and group critical thought regarding the neighborhood's challenges, and at the same time reinforcing the participants' awareness of their role in the community. A focus group was established for that purpose, guided by questions as proposed by the SHOWeD method
(Wallerstein, 1987): "What do you see in the photo? What is really happening here? How do you think it influences your lives? Why do you think this situation (strength or challenge) exists? What do you think you can do about this situation?" Afterward, an initial selection of the most meaningful photos took place, and each participant gave them a title.

The objective of the third meeting was to reflect on changes participants would like to see in the neighborhood and what actions they could take to set those changes in motion. Two community arttherapists were involved in this phase, making it possible to integrate arttherapy techniques into the photovoice process. The participants were given the task of creating, on a poster board, the front page of a newspaper with articles related to positive changes happening in the neighborhood. Facilitators encouraged participants to use several clippings provided and their own photos about the neighborhood. They painted over their photos to better express the ideas they wanted to convey. At the end of the meeting, each participant showed the group her own piece and explained her ideas on how to enact the desired change. The proposals were then discussed by the group. The meeting ended with planning the final exhibition.

The final exhibition took place during the youth organization's party at the end year. The event was attended by more than 100 visitors, among them the participants' families, local representatives of the area, and community neighbors. Using posters located at the sides of the photography exhibition, a space was created where the visitors could express their own opinions regarding changes they would like in the neighborhood and what they themselves could do to enact these changes. During the party the participants had the task of showing and explaining the photos to the visitors, and then inviting them to leave their opinions and vote for the most 
meaningful photo. This activity was planned in order to give the participants an opportunity to show their abilities to the extended community, to communicate to others their experiences and reflections, and to encourage these teenagers to become active agents of change in their own community. The high level of participation at the final exhibition gave the photographs great visibility and provided an intense exchange of opinions regarding the represented themes. Finally, the post-test was administered, and the awards were given to participants: certificates of participation to all participants and a camera to the teenager who earned the most votes for their photo from the community.

The three formal meetings were audiorecorded, and the transcribed narratives were analyzed with Atlas-ti software (version 6) by the research team. With the purpose of evaluating the evolution of the variables of interest during the meetings, the verbatim transcripts were analyzed using the following categories: "psychological sense of community", "future participation", and "empowerment". Additionally, the research team analyzed the 37 photographs produced by the participants as well as the impressions reported by the extended community during the final exhibition. The purpose of the analysis was to understand the community's impressions about the neighborhood and the effect of the photovoice process at a community level.

In addition, measurements through the questionnaire were taken before and after the photovoice implementation to evaluate the effects of the researchintervention on the grade of youth neighborhood activism. An experimental social innovation (Hazel \& Onaga, 2003) was carried out through which the photovoice was implemented in the participant group and compared with a comparison group. This means that assignment to the comparison condition is nonrandom, but both the participant and comparison groups are similar in terms of socioeconomic status, race, gender, age, etc. Quantitative data were analyzed using the software SPSS (version 20), through a non-parametrical statistical contrast of pre-test and a posttest with a comparison group, specifically the Wilcoxon-Mann-Whitney test, which is more accurate than independent samples Student's $t$-test for the characteristics of the sample.

\section{Results}

Results are ordered by the theoretical variables of interest related to youth neighborhood activism, i.e., psychological sense of community, forecast of future participation, and empowerment. Both the quantitative and qualitative data are shown, which bring light to participants' experiences in relation to each of these variables during the photovoice process. Table 1 shows the descriptive and contrast analysis for each variable, in function of the group (participant or comparison), and the moment of evaluation (before or after the photovoice implementation). In a previous phase, the Wilcoxon-MannWhitney test confirmed how significant differences between the participant and comparison group in either variable of interest did not exist before the photovoice implementation (analysis are not shown). This indicates participants were similar in variables of interest before the intervention.

\section{Psychological Sense of Community}

Data related to psychological sense of community show significant differences between before and after the photovoice implementation in the participant group (see Table 1). This means that, while for the comparison group the mere passage of time does not generate any change, the members of the participant group reached a greater psychological sense of community during the program of intervention (from 2.60 to 3.08 points). Due to the design of evaluation, these 


\begin{tabular}{llcccc}
\cline { 3 - 6 } & & Pre-test & Post-test & $\boldsymbol{Z}$ & $\boldsymbol{p}$ \\
\hline Participant group & $\bar{X}(S)$ & $2.60(0.79)$ & $3.08(0.44)$ & -1.99 &. $\mathbf{0 2}$ \\
\hline \multirow{2}{*}{ Psychological sense of community } & $N$ & 8 & 6 & & \\
\hline \multirow{2}{*}{ Forecast of future participation } & $\bar{X}(S)$ & $3.03(1.16)$ & $3.87(0.59)$ & -2.00 &. $\mathbf{0 2}$ \\
\hline \multirow{2}{*}{ Empowerment } & $N$ & 8 & 6 & & \\
\hline Comparison group & $\bar{X}(S)$ & $3.07(0.71)$ & $3.13(0.60)$ & -.42 & .34 \\
\hline \multirow{2}{*}{ Psychological sense of community } & $N$ & 8 & 6 & & \\
\hline \multirow{2}{*}{ Forecast of future participation } & $\bar{X}(S)$ & $2.82(0.56)$ & $2.76(0.67)$ & -.14 & .44 \\
\hline & $N$ & 8 & 8 & & \\
\hline Empowerment & $\bar{X}(S)$ & $2.18(0.74)$ & $2.20(1.00)$ & -.11 & .46 \\
\hline & $N$ & 8 & 8 & & \\
\hline
\end{tabular}

Table 1: Descriptive and Contrast Analysis on the Variables Related to Youth Neighborhood Activism for Both the Participant and Comparison Group, Before and After the Intervention through Photovoice Note: Analysis from Wilcoxon-Mann-Whitney test (two-tailed test).

changes are attributable to the influence of the photovoice process on the participants. Complementary to these data, a similar finding emerged from the qualitative data. The analyses of the 37 photographs and the codification of the narratives made it possible to identify what the participants considered their community's main strengths and challenges. The photographs showed the places of community life; the narratives expressed the actors and plots of these places. Participants were encouraged to be aware of those things that characterize their neighborhood. This allowed participants to notice the key effects their place of residence has on their lives and to reinforce the sense of belonging to their community. The main themes arising from the photographs are presented below.

Community strengths. The majority of strengths identified by the participants refer to (a) the community's public services, (b) the gathering places, and (c) the fact that they are a multicultural community.

One of the neighborhood's most important public services is the public library, which was recently built and is used especially by the local youth. Also, the new subway stop in the neighborhood has given their inhabitants connection to the rest of the city. From the descriptions of the photographs, the importance of the subway stop was not only as a way to move from place to place faster, but also a way to guarantee nighttime connection 
and create new leisure opportunities for youth.

The importance of gathering places derives from the awareness that they are places where one can experience reciprocal trust and sharing, thereby contributing to social networks in the community. A photo showing the neighborhood café was described by a participant as "a little place, but where there's always a great atmosphere". In relation to green areas in the neighborhood, another participant told us, "In this photo we see El Pruno park, which I think is amazing [...] Many people go there, kids can go, even really little ones [...] There's an association of parents who take responsibility for cleaning it, who have keys to it."

In relation to the fact of being a multicultural community and, as a consequence, having the opportunity to enjoy numerous and diverse religious gatherings, participants clearly expressed a sense of social cohesion and sense of belonging. They are proud of being an "international neighborhood", where people think of their neighbors as sources of support. Participants feel the neighborhood has the capacity of integrating culturally diverse neighbors, and they all recognize themselves as "people from Su Eminencia". The neighborhood's Catholic procession (a religious tradition during Easter week), which is well-known and admired from other areas in the city, has a great influence on the teenagers. A participant expressed her feelings in this way: "Seeing the people who came [to the procession] made a strong impact [...] It cheered me up a lot because I was at the procession, and it's really nice that the believers have the Virgin in their blood."

Community challenges. The majority of challenges identified by the participants refer to (a) the high rate of unemployment and the neighbors' economic problems and (b) the drug dealing and addiction by the neighborhood's young people.
Accordingly, many of the neighbors expressed challenges during the final exhibition similar to those declared by the teenagers.

Related to the unemployment problem, one photo showed a man inside a dumpster with the "intent of finding something to sell". Photovoice fueled a high awareness of the state of need of many of the neighbors due to an increase in unemployment. In the face of this situation, participants declared a compassionate feeling towards their neighbors. As a participant expressed: "I understand that he's needy, he doesn't have anything else, and he's looking for something to sell because he doesn't have a job... what they [the government] should do is give an opportunity to so many people who don't have jobs, who can only get something to eat out of the trash." In spite of such phenomena mainly affecting the adult sphere, the awareness of such precarious situations emerged as a latent worry which is reflected in the teenagers' perspective of future.

A photograph showing an abandoned building with syringes was selected by the participants as a symbol of the drug-related issues characterizing their neighborhood. A deep awareness emerged from the photovoice meetings about the neighborhood's "drug areas". The use of drugs is viewed by the participants as both a cause and an effect of the lack of employment. The teenagers thinking about the drug addicts as "needy people" did not lead them to judge severely, but, by contrast, they revealed a high level of empathy towards them. As one participant defended: "They aren't bad people, there are good ones and bad ones [...] I really pity them and I put myself in their position and I'd feel terrible too in their place. People who get mixed up in drugs do it because something 
has happened to them. It isn't just a bad habit, but because a person isn't very strong, or also because they don't know how to deal with things."

\section{Forecast of Future Participation}

Concerning the quantitative data, contrast analysis showed that after the intervention, significant differences existed in the degree of forecast of future participation depending on the group. After the intervention, the participant group presented a greater interest to be involved in activities that help to improve the neighborhood, in comparison to the participants from the comparison group (from 3.03 to 3.87 points; see Table 1). These results seem to be attributable to the influence of the intervention.

The qualitative data refer to the increase in critical thinking among the participants about the neighborhood's challenges as a first step to want to be involved in the process of change. In relation to the neighborhood's dirtiness, the neighborhood is not regularly served by the city street cleaning service and, to deal with the large quantity of garbage, the inhabitants burn the dumpster contents causing foul fumes. In words from a participant: "It's also a fact that there are only two dumpsters and before there were a lot of other ones, and the street cleaners come, at most, two times a year. They just don't come. They come when they feel like it. Sometimes they come and sometimes they don't." To face this situation and others, participants expressed their interest in initiatives focused on themes such as cleaning up the streets and respect for parks. In general terms, a participant stated the group's feeling: "What we want is for people to take care of the neighborhood, young people should do their part, and say how they can help, give their opinion".

Participants' interest in using community activities to improve their neighborhood was fueled by the interchange of opinions they had with the neighbors during the final exhibition. Among the activities people wanted to do in the shortmedium term were to separate the garbage and recycling, not litter, not graffiti the walls, not break objects that are for public use, smile at everybody, live harmoniously with neighbors, learn to share, know how to be content with oneself, work together towards the same goals, and get coordinated to change and improve the neighborhood.

\section{Empowerment}

From the contrast analyses, no significant changes were found between "before" and "after", inside the group of comparison or inside the participant group (see Table 1). For this variable, changes did not take place in the participant group as a consequence of photovoice implementation.

During the photovoice process, the participants expressed a notable vitality in putting forward proposals to improve the neighborhood; however, narratives suggest that gaining awareness of one's own potential to enact change needs a more specific intervention and a longer period of time to be affirmed as a transformative competency. In this sense, there was a tendency among the participants to contemplate the involvement of institutions as a first step towards resolving the neighborhood's challenges. In relation to the meetings' recordings, a participant told us: "You know what you could do with this video? Take it to the mayor and to the people who fix things [...] so that they will see what the neighborhood is like". On one hand, this could imply the desire to denounce the identified issues; on the other one, this could infer a behavior of delegating problem resolution to adults and the authorities. By further exploring the problem of the presence of drugs in the neighborhood, the possibility of 
fighting it, and the desire to make oneself useful in that respect, a similar sense of impotence emerged regarding the ability to do something effective: "If I could do something for the drug addicts I would do it". Although participants increased their conviction about the possibility of overcoming difficulties, the photovoice process was not useful for giving them a clear direction to transform their desires of change into concrete actions. Participants do not feel that they themselves are capable to overcome their neighborhood's challenges. As a consequence, attitudes of impotence and demands directed to powerful people to fix their problems exist in the teenagers.

At the conclusion of the project the participants were asked if they felt the photovoice process had provoked any changes in themselves. The response was unanimous and affirmative. Some replied that the project "made them see things in a different way". Other participants replied that, thanks to an increased awareness of the strengths they can rely on, they themselves will be the ones to influence their neighborhood. However, the intervention failed in its objective of increasing the empowerment level of the participants as an essential element for neighborhood activism.

\section{Discussion}

The research-intervention process carried out in this study through photovoice increased the level of psychological sense of community and the wish for future participation in a group of teenagers who live in a vulnerable, multi-cultural neighborhood of southern Spain; however, their degree of empowerment did not change. This pilot study followed a researchintervention approach, where the diagnosis of the situation of teenagers who live in a vulnerable neighborhood met with an intervention aimed at increasing the participants' neighborhood activism. For this reason, this study considered the research process not to be a simple collection of data, but also a stimulus for sharing impressions about their own neighborhood, for the development of critical reflection about their community, and for the reinforcement of hope in the possibility of bringing about change. An evaluation design with data collection from diverse sources, i.e. through a triangulation process with quantitative and qualitative data, was used to assure the intervention's effects. As a consequence, photovoice was demonstrated as a tool capable of opening up new opportunities for increasing neighborhood activism among young populations and thus, breaking the vicious cycle of vulnerability by transforming neighborhoods into fairer ones.

Results suggest that teenagers from the participant group reached a greater degree of psychological sense of community through the intervention program than the comparison group. This result is consistent with previous findings in the literature that showed young people involved in producing awareness for action in their communities developed a strong sense of community and responsibility to others (Wong, Zimmerman, \& Parker, 2010). The photovoice process allowed participants to think critically about the challenges of their neighborhood and to give value to its strengths, favoring the development of a deeper sense of community. This process made possible the transformation of individual photographs into a group product that gathered the vision of the teenagers in relation to their neighborhood.

In relation to community participation, after the intervention the participant group presented a greater interest to be involved in activities that help to improve their neighborhood compared to the comparison group. This result is in line with the 2007 study carried out by Foster-Fishman and colleagues, 
which found that people who recognize both the neighborhood's strengths and challenges are more likely to participate in neighborhood change strategies. Using the neighborhood's detailed picture made together by the teenagers, participants were called to imagine the desired changes they would like to see in their environment and to reflect on their role in that transformation process. Photovoice triggered a process of raising-consciousness about their neighborhood, thus provoking a renewed interest in their social sphere and nurturing the desire to actively be a part of it.

Significant changes were not obtained in regard to the empowerment of the participant group. Although the photograph exhibition was organized with the objective of increasing the teenagers' sense of power to act and change the neighborhood, the results suggest that was not enough. As suggested by Wong, Zimmerman, and Parker (2010), this may be explained because the type of researchintervention process carried out. The authors show that adult-driven interventions, although able to impact a number of dimensions of youth development, might not increase their level of empowerment. This pilot study did not include a young-driven process, since the young community was not involved during the planning of the intervention program (that is, the decision-making or agenda setting process was defined with the organization's staff, but not with the young people).

The dynamic of positive feedback that could flourish between youth neighborhood activism and the transformation of vulnerable neighborhoods is of great interest for community researchers. Teenagers can be made aware that the cause of several of their problems is not inside them, but produced by their environment. In this case, young people can develop neighborhood activism, perceiving themselves as empowered persons with the possibility of influencing their future. Through their community participation, together with others in the same situation, they can transform those contextual conditions that impede their well-being. These changes in the neighborhood would contribute to opportunities for youth to meet their needs and reach well-being. Likewise, the perception of being an active and integrated member of the community has a positive influence on one's selfimage, self-esteem, and personal control, helping to break the vicious cycle of oppression (Cowen, 2000). This study suggests that photovoice could be a useful tool that contributes to work in this direction; however, this study has several limitations.

First, the modest number of participants in this study cannot be generalized to include all sections of youth residing in the "Su Eminencia" neighborhood. However, the use of a small group was fundamental for obtaining these results because it made possible the creation of a protected space which facilitated the expression of thoughts and emotions. The sharing of experiences inside a group allowed for the activation and discovery of previously unknown individual and community resources and favored processes of reassigning meaning to the experience itself. In addition, the participants' involvement during the meetings allowed for the breaching of delicate themes such as drug dealing which, although recognized by all, are often not openly dealt with.

Second, the results regarding empowerment suggest that for future research-intervention, it could be interesting to increase the active presence of youth during all phases of the process. In addition, it is necessary to include some proposals of concrete actions to carry out with the teenagers. In this way, young people will be able to experience the 
possibility of change and to feel like they themselves have the power to make small changes in their environment, thus increasing their degree of empowerment. Beyond activities for raising awareness about how their neighborhood is, its influence in their life, how they would like their neighborhood to be, and how they could change their environment to reach that goal, future interventions could offer concrete channels of action on how to make these detected changes a reality. More focused, participative, and longer lasting interventions are necessary to internalize all suggested.

This pilot study suggests the use of artistic tools can make it possible to imagine alternative ways to be around others, such as creating and giving new meaning to the participants' experiences in the community (Daher \& Haz, 2011; Slayton, 2012). The active participation shown by the extended community at the final photography exhibition demonstrated photovoice's generative powerto involve vulnerable communities in acts of participation. Photovoice's attractiveness hooked the participants and encouraged a part of the population reluctant to open themselves up to the outside world to get involved. During the photovoice process, they had the chance to express for the first time their own ideas and feelings through photographs and art. The use of research-intervention through photovoice is an innovative and flexible tool able to trigger a process toward gaining awareness of their vulnerable context's strengths and challenges, evaluating their own role in the environment's dynamics, and leading to an increase in youth neighborhood activism aimed at transforming the neighborhood into a fairer one.

\section{References}

Aguiar, J. (2013). Empowerment-a relational challenge. Global Journal of Community Psychology Practice, 3 (4), 1-4.

Ayuntamiento de Sevilla (2012). Boletín demográfico de la ciudad de Sevilla. Sevilla, España: Junta de Andalucía.

Baker, T. A., \& Wang, C. C. (2006). Photovoice: Use of a participatory action research method to explore the chronic pain experience in older adults. Qualitative Health Research, 16 (10), 1405-1413.

Balcazar, F., Suarez-Balcazar, Y., Bibiana, S., Keys, C.B., García-Ramírez, M., \& Paloma, V. (2012). A case study of liberation among Latino immigrant families who have children with disabilities. American Journal of Community Psychology, 49, 283-293.

Chavis, D. M., Lee, K. S., \& Acosta, J. D. (2008). The sense of community (SCI) revised: The reliability and validity of the SCI-2. Paper presented at the 2 nd International Community Psychology Conference, Lisboa, Portugal.

Cicognani, W., Zani, B., \& Albanesi, C. (2008). Sense of community in adolescence. Global Journal of Community Psychology Practice, 3 (4), 118-125.

Cotterell, J. (1996). Social networks and social influences in adolescence. London: Routledge.

Cowen, E. L. (2000). Psychological wellness: Some hopes for the future. In R. P. Weissberg (Ed.), The promotion of wellness in children and adolescents (pp. 309-339). Washington, DC: CWLA Press. 
Daher, M., \& Haz, A.M. (2011). Changing meanings through art: A systematization of a psychosocial intervention with Chilean women in urban poverty situation. American Journal of Community Psychology, 47, 322-334.

Dumont, M., \& Provost, M.A. (1999). Resilience in adolescents: Protective role of social support, coping strategies, self-esteem, and social activities on experience of stress and depression. Journal of Youth and Adolescence, 28 (3), 343-363.

Foster-Fishman, P.G., Cantillon, D., Pierce, S., \& Van Egeren, L.P. (2007). Building an active citizenry: The role of neighborhood problems, readiness, and capacity for change. American Journal of Community Psychology, 39, 91106.

Garcia, I., Giuliani, F., \& Wiesenfeld, E. (1999). Community and sense of community: The case of an urban barrio en Caracas. Journal of Community Psychology, 27 (6), 727-740.

García-Ramírez, M., Albar, M. J., \& Paloma, V. (2010). Migrant liberation psychology: Coalition for the study of health, power and diversity. The Community Psychologist, 43 (1), 5-6.

Gilster, M.E. (2012). Comparing neighborhood-focused activism and volunteerism: Psychological well-being and social connectedness. Journal of Community Psychology, 40 (7), 769-784.

Hazel, K.L. \& Onaga, E. (2003). Experimental social innovation and dissemination: The promise and its delivery. American Journal of Community Psychology, 32 (3/4), 285-294.
Herrero, J. \& Gracia, E. (2007). Measuring perceived community support: Factorial structure, longitudinal invariance and predictive validity of the PCSQ (Perceived Community Support Questionnaire). Journal of Community Psychology, 35, 197 217.

Israel, B. A., Checkoway, B., Schulz, A., \& Zimmerman, M. (1994). Health education and community empowerment: Conceptualizing and measuring perceptions of individual, organizational, and community control. Health Education \& Behavior, 21 (2), 149-170.

Kelly, D.C. (2009). In preparation for adulthood: Exploring civic participation and social trust among youth minorities. Youth \& Society, 40 (4), 526-540.

Killion, C. M., \& Wang, C. C. (2000). Linking African American mothers across life stage and station through photovoice. Journal of Health Care for the Poor and Underserved, 11 (3), 310-325.

Martín-Baró, I. (1987). El latino indolente: Carácter ideológico del fatalismo latinoamericano. In M. Montero (Coord.), Psicología Política Latinoamericana (pp. 135-162). Caracas: Editorial Panapo.

McMillan, D.W., \& Chavis, D.M. (1986). Sense of community: A definition and a theory. Journal of Community Psychology, 14, 6-22.

Moane, G. (2003). Bridging the personal and the political: Practices for a liberation psychology. American Journal of Community Psychology, 31 (1/2), 91-101.

Montero, M. (2006). Hacer para transformar: El método en la psicología comunitaria. Buenos Aires: Paidós. 
Nicotera, N. (2007). Measuring neighborhood: A conundrum for human services researchers and practitioners. American Journal of Community Psychology, 40, 26-51.

Oliffe, J. L., \& Bottorff, J. L. (2007). Further than the eye can see? Photo elicitation and research with men. Qualitative Health Research, 17 (6), 850-858.

Paloma, V., \& Manzano-Arrondo, V. (2011). The role of organizations in liberation psychology: Applications to the study of migrations. Psychosocial Intervention, 20 (3), 309-318.

Pretty, G.H., Conroy, C., Dugay, J., Fowler, K., \& Williams, D. (1996). Sense of community and its relevance to adolescents of all ages. Journal of Community Psychology, 24, 365380.

Prezza, M., Pilloni, S., Morabito, C., Sersante, C., Alparone, F.R. \& Giuliani, M.V. (2001). The influence of psychological and environmental factors on children's independent mobility and relationship to peer frequentation. Journal of Community \& Applied Social Psychology, 11 (6), 435-450.

Putman, R. (2000). Bowling alone: The collapse and revival of American community. New York: Simon \& Schuster.

Rankin, B.H., \& Quane, J.M. (2002). Social contexts and urban adolescent outcomes: The interrelated effects of neighborhoods, families, and peers on AfricanAmerican youth. Social Problems, 49 (1), 79-100.

Rappaport, J. (1987). Terms of empowerment/exemplars of prevention: Toward a theory for community psychology. American Journal of Community Psychology, 15 (2), 121-148.
Slayton, S.C. (2012). Building community as social action: An art therapy group with adolescent males. The arts in Psychoterapy, 39, 179-185.

Soriano, E., \& Cala, V. C. (2014). Study on the Cultural Differences Regarding Health Using the Photovoice. A Qualitative Study Involving Romanian and Spanish Adolescents in Southern Spain. Procedia-Social and Behavioral Sciences, 132, 65-73.

Strack, R.W., Magill, C., \& McDonagh, K. (2004). Engaging youth through photovoice. Health Promotion Practice, 5 (1), 49-58.

Suarez-Balcazar, Y., Harper, G., \& Lewis, R. (2005). An interactive and contextual model of communityuniversity collaborations for research and action. Health Education \& Behavior, 32 (1), 84101.

Tartaglia, S. (2006). A preliminary study for a new model of sense of community. Journal of Community Psychology, 34 (1), 25-36.

Torres, F.J. (2005). El análisis territorial aplicado al estudio de zonas urbanas marginadas: El caso de Polígono Sur en Sevilla. Sevilla, España: Junta de Andalucía.

Torres, F.J. (2011). Periferia mundial, periferia local: Consideraciones socio-territoriales sobre el asentamiento de población inmigrante en Sevilla. En F.J. García-Castaño y N. Kressova (Coord.), Actas del I Congreso Internacional sobre Migraciones en Andalucía (pp. 1835-1847). Granada, España: Instituto de Migraciones. 
Vieno, A., Nation, M., Perkins, D.D., \& Santinello, M. (2007). Civic participation and the development of adolescent behavior problems. Journal of Community Psychology, 35 (6), 761-777.

Wallerstein, N. (1987). Empowerment education: Freire's ideas applied to youth. Youth Policy, 9, 11-15.

Wang, C.C., \& Burris, M.A. (1997).

Photovoice: Concept, methodology, and use for participatory needs assessment. Health Education \& Behavior, 24 (3), 369-387.

Wang, C.C., Morrel-Samuels, S., Hutchison, P.M., Bell, L., \& Pestronk, R.M. (2004). Flint photovoice: Community building among youths, adults, and policymakers. American Journal of Public Health, 94 (6), 911-913.

Wilson, J. (2000). Volunteering. Annual Review of Sociology, 26, 215-240.

Wilson, N., Dasho, S., Martin, A. C., Wallerstein, N., Wang, C. C., \& Minkler, M. (2007). Engaging young adolescents in social action through Photovoice: The Youth Empowerment Strategies (YES!) project. Journal of Early Adolescence, 27 (2), 241-261.

Wong, N.T., Zimmerman, M.A., \& Parker, E.A. (2010). A typology of youth participation and empowerment for child and adolescent health promotion. American Journal of Community Psychology, 46, 100114.
Zimmerman, M.A. (2000). Empowerment theory: Psychological, organizational, and community levels of analysis. In J. Rappaport and E. Seidman (Eds.), Handbook of community psychology (pp. 4363). New York: Kluwer /Plenum.

Zimmerman, M.A. \& Rappaport, J. (1988). Citizen participation, perceived control, and psychological empowerment. American Journal of Community Psychology, 16 (5), 725-750. 